\title{
Gene therapy strategies using engineered stem cells for treating gynecologic and breast cancer patients (Review)
}

\author{
YE-SEUL KIM, KYUNG-A HWANG, RYEO-EUN GO, CHO-WON KIM and KYUNG-CHUL CHOI \\ Laboratory of Biochemistry and Immunology, College of Veterinary Medicine, Chungbuk \\ National University, Cheongju, Chungbuk 361-763, Republic of Korea
}

Received August 20, 2014; Accepted February 9, 2015

DOI: 10.3892/or.2015.3846

\begin{abstract}
There are three types of stem cells: embryonic stem (ES) cells, adult stem (AS) cells and induced pluripotent stem (iPS) cells. These stem cells have many benefits including the potential ability to differentiate into various organs. In addition, engineered stem cells (GESTECs) designed for delivering therapeutic genes may be capable of treating human diseases including malignant cancers. Stem cells have been found to possess the potential for serving as novel delivery vehicles for therapeutic or suicide genes to primary or metastatic cancer formation sites as a part of gene-directed enzyme/prodrug combination therapy (GEPT). Given the advantageous properties of stem cells, tissue-derived stem cells are emerging as a new tool for anticancer therapy combined with prodrugs. In this review, the effects of GESTECs with different origins, i.e., neural, amniotic membrane and amniotic fluid, introduced to treat patients with diverse types of gynecologic and breast cancers are discussed. Data from the literature indicate the therapeutic potential of these cells as a part of gene therapy strategies to selectively target malignancies in women at clinically terminal stages.
\end{abstract}

\section{Contents}

1. Introduction

2. Gynecologic cancers

3. Breast cancer

4. Other origins of stem cells

5. Conclusion

Correspondence to: Professor Kyung-Chul Choi, Laboratory of Biochemistry and Immunology, College of Veterinary Medicine, Chungbuk National University, Cheongju, Chungbuk 361-763, Republic of Korea

E-mail: kchoi@cbu.ac.kr

Key words: stem cells, gene therapy, gynecologic cancers, breast cancers

\section{Introduction}

Gene/prodrug systems can be used to selectively target malignant cancer cells while leaving normal cells unharmed. Thus, application of these systems to reduce undesirable side-effects has recently received increased attention (1). A gene therapeutic system using cytosine deaminase (CD)/5-fluorocytosine (5-FC) (2-4), a gene-directed enzyme/prodrug therapy (GEPT) that currently exists, involves the conversion of a nontoxic drug (5-FC) into the toxic metabolite 5-fluorouracil (5-FU), an active anticancer drug that inhibits DNA synthesis in cancer cells (5). In addition, herpes simplex virus thymidine kinase (HSV-TK) suicide gene and its complementary prodrug ganciclovir (GCV) have been used to selectively target human types of cancers, indicating a potential therapeutic use of this gene delivery for primary human types of cancers (6). This GEPT system has been used to treat various types of cancer including colorectal and prostate cancer in clinical trials $(7,8)$. In addition, CPT-11, which is hydrolyzed into a topoisomerase 1 inhibitor (SN-38) by carboxyl esterase (CE), has been administered to cancer patients, including ones with colorectal cancer for decades (9). Prodrugs appear to be associated with reduced toxicity in normal tissues but there are potential problems with exogenous enzyme delivery for selectively targeting tumor cells.

Stem cells are characterized by both self-renewal and the ability to differentiate into various cell types (10). However, the applications of embryonic stem (ES) cells taken from a developing human embryo are linked to numerous ethical issues. Therefore, the therapeutic use of these stem cells has been extremely restricted $(11,12)$. Recently, stem cell therapy using multi-pluripotent stem cells has been used for treating malignant cancer and promoting the self-renewal of damaged tissues $(13,14)$. Adult stem (AS) cells including neural stem cells (NSCs), mesenchymal stem cells (MSCs), and umbilical cord-derived MSCs are easily obtained and have been successfully used in numerous patients (15). Genetically engineered NSCs as a component of GEPT can serve as a potent gene delivery entity that selectively targets and kills cancer cells following systemic treatment with a prodrug (16). In particular, NSCs derived from medulloblastomas and gliomas have a great potential for treating malignant brain cancer $(17,18)$.

Although the exact mechanism(s) that govern how NSCs selectively migrate to tumor sites are not fully understood, 
these cells have been used to deliver therapeutic molecules in patients with disseminated metastatic cancers $(19,20)$. In this review, we discuss several types of stem cells that can selectively deliver therapeutic genes in both in vitro and in vivo models of gynecologic and breast cancers. Of particular interest is that the tropism of these stem cells can help target intra- and extra-cranial tumors of both neural and non-neural origins $(19,21)$. Previous studies showed that HB1.F3 human NSCs migrate to xenografted tumors derived from diverse human cancers including prostate cancer, neuroblastomas, gliomas and breast lesions $(7,18,22-24)$. Although these stem cells do not have a tissue-specific homing capability, they could be useful for directly killing malignant tumors due to their ability to migrate to tumor sites in general $(7,18,25,26)$. The findings published in the literature indicate that therapeutic stem cells with specific tumor tropism can be used for targeted gene therapy to treat gynecologic and breast cancers in women at terminal stages.

\section{Gynecologic cancers}

Ovarian cancers. Although ovarian cancer has a significant impact upon women's health, the mechanism(s) underlying the conversion of normal ovarian surface epithelial (OSE) cells into malignant counterparts and its developmental process remain unclear (27). To enhance the effectiveness of therapeutic modalities for eradicating ovarian cancer, novel strategies are necessary $(28,29)$. To confirm the potential effect of a GEPT protocol using genetically engineered NSCs on ovarian cancer, we studied the therapeutic effects of HB1.F3.CE on SKOV-3 ovarian cancer cells under the treatment of CPT-11 (30). Administration of CPT-11 not only reduced the number of HB1.F3.CE cells but also inhibited the growth of untransfected neighboring ovarian cancer cells through a bystander effect.

Other previous studies demonstrated that immune responses or apoptotic factors may be involved in GEPT-induced bystander effects $(31,32)$. However, further study is required to clarify the mechanism underlying these bystander effects in diverse human cancers. In previous studies using diverse models for human cancers, a GEPT system including CD/5FC or CE/CPT-11 induced antitumor effects in vivo $(17,18)$. In addition, results of the above studies showed that genetically engineered stem cells (GESTECs) expressing CD/CE may have the ability to selectively migrate toward and directly kill ovarian cancer cells. A recent study demonstrated that the reconstructed MSCs expressing both TK and CD vectors were capable of slowing down the growth of human SKOV-3 ovarian cancer cells in the presence of prodrugs in vitro, indicating that the use of combination chemotherapy exhibited a more significant inhibitory effect than using a single prodrug (33).

In addition, intraperitoneal injections of IFN- $\beta$-expressing MSCs resulted in complete eradication of tumors in $70 \%$ of OVCAR-3 xenografted mice and an increased survival of SKOV-3 xenografted mice (34). As a potential mechanism of tumor eradication, it can be suggested that ovarian carcinoma engrafts MSCs to participate in myofibrovascular networks and IFN- $\beta$ produced by MSCs intratumorally modulates tumor kinetics by producing IFN- $\beta$-induced caspase-dependent tumor cell apoptosis, resulting in prolonged survival in animal models (34). Taken together, this GEPT system resulted in an antiproliferative effect on ovarian cancer cells, suggesting that GESTECs expressing therapeutic genes in the presence of prodrugs may have therapeutic potential for selectively targeting ovarian malignancies in female patients (30).

Endometrial cancer. Every year, approximately 40,000 new cases of endometrial cancer are diagnosed in the US and $\sim 7,000$ women succumb to this disease each year. Thus, endometrial/uterine cancer is the fourth most common malignancy and the eighth leading cause of cancer-related death among women in the US (35). The exact factors responsible for the pathogenesis and progression of endometrial cancer are poorly understood although extensive research on this type of cancer is currently ongoing. Treatment for endometrial cancer includes several types of approaches such as surgical removal of the uterus, radiation, hormone therapy and chemotherapy $(36,37)$. Among these methods, chemotherapy and radiotherapy have been most commonly used. However, the accompanying sideeffects are serious and these modalities are associated with a high risk of recurrence $(38,39)$.

Stem cell-based gene therapies may be a potential alternative treatment for many types of human cancer. The therapeutic potential for treating cancer with human NSCs immortalized by a retroviral vector has been evaluated (40). In our previous study, we tested the hypothesis that human NSCs genetically engineered via gene transfer are highly effective for eradicating endometrial cancer cells (41). Although an accurate molecular mechanism underlying the tumor-tropism of these stem cells has not been clearly elucidated, the tumor-tropic activities of HB1.F3.CD and HB1.F3.CD.IFN- $\beta$ cells can provide an excellent method for specifically and selectively targeting endometrial cancer. The tumor cell derived factors, such as SDF-1, scatter factor, VEGF and macrophage chemotactic protein-1 (MCP-1), which may serve as chemoattractants, were carefully scrutinized to explain the tumor-tropism of stem cells toward targeted cancer cells $(17,42)$.

Cervical cancer. It is expected that the occurrence of cervical cancer will be decreased due to the development of the human papilloma virus (HPV) vaccine. However, cervical cancer still remains a significant public health issue for women (43). According to the World Health Organization (WHO), cancer of the cervix uteri is the second most common malignancy among women worldwide with an estimated 529,400 new cases and 274,900 deaths in 2008 (44). Approximately $86 \%$ of cervical cancer cases occur in developing or underdeveloped countries, representing $13 \%$ of cancer cases in females (45). Although hysterectomy is the best preventive method for cervical cancer, this therapy causes sterility in patients. To reduce the sterility of women with cervical cancer, more efficient treatments against this disease are required.

GESTECs have been employed to treat cervical cancers in a xenograft mouse model (46). In this study, the viability of HeLa cells was decreased in response to 5-FC, indicating that the prodrug was converted into the toxic 5-FU metabolite by $\mathrm{CD}$ and led to cell death in a co-culture system with GESTECs. When IFN- $\beta$ was additionally expressed with CD by the stem cells, the anticancer activity was significantly increased (46). Results of a migration assay demonstrated that 
the stem cells also selectively migrated to the HeLa cells. To verify the role of vascular endothelial growth factor (VEGF) in cell migration, we previously attenuated the function of VEGFR2 produced by stem cells with KRN633, a selective VEGFR2 inhibitor, and confirmed that the number of migrating stem cells was decreased to $48.6 \%$ for HB1.F3.CD cells and $63.2 \%$ for HB1.F3.CD.IFN- $\beta$ cells compared to untreated GESTECs (46). These results indicate that VEGF and VEGFR2 may play a crucial role in the migration of stem cells expressing CD and/or IFN- $\beta$ toward HeLa cells as observed in other studies $(47,48)$.

\section{Breast cancer}

Breast cancer is the most common malignancy impacting the health of women worldwide with an incidence rate that increases each year (49). In addition to this increase of occurrence, breast cancer is the leading cause of death among women due to uncontrolled cell growth, invasion and metastasis (49). Similar to other types of cancer, chemotherapy is the main treatment for breast cancer patients with advanced metastatic disease (50). Conventional chemotherapeutic drugs including 5-FU, irinotecan, oxaliplatin, chlorambucil, taxol and vincristine have been widely used, yet these compounds are sometimes associated with disease resistance, toxicity and other undesirable side-effects (49). Consequently, there is a substantial need for novel, effective and safe therapies for patients with aggressive breast cancer.

As previously mentioned, therapeutic stem cells are anticipated to be an effective tumor-targeting anticancer agent. Indeed, multiple types of stem cells engineered to express anticancer or therapeutic genes at a specific tumor locus have been reported to significantly inhibit aggressive tumors $(13,17,22,51-54)$. Furthermore, some reports indicated that non-engineered native stem cells may also have an inherent ability to prevent the growth of several types of cancer cells (55). While GESTECs cannot help overcoming problems associated with the expression of exogenous genes such as mutation, inappropriate insertion into genomic DNA and viral vector virulence, non-engineered native stem cells have advantages in terms of patient safety. The anticancer effect of human amniotic membrane-derived epithelial stem cells (hAECs) may be associated with growth inhibitors produced by the hAECs themselves along with the tumor targeting capacity of the cells (49). It is well known that diverse types of factors such as transforming growth factor- $\beta$ (TGF- $\beta$ ), interferon- $\gamma$ (IFN- $\gamma$ ) and tumor necrosis factor- $\alpha$ (TNF- $\alpha$ ) secreted by stem cells can inhibit the cell cycle and stimulate apoptosis of cancer cells (49). A cytokine assay confirmed that hAECs express not only cytotoxic cytokines such as macrophage-colony stimulating factor (M-CSF), TNF- $\alpha$, TNF- $\beta$, IFN- $\gamma$ and TGF- $\beta$, yet also numerous interleukins such as interleukin (IL)-1, IL-2, IL-3, IL-4, IL-6 and IL-8 (49). Factors such as IL-2, IL-4 and IL-3 are known to enhance the cytotoxicity of natural killer (NK) cells which can attack cancer cells and restrict tumor formation (49). The mechanisms by which hAECs exert their anticancer effects on breast tumors or other lesions should be further clarified.

Human amniotic fluid-derived stem cells (hAFSCs) are capable of multiple lineage differentiation, extensive self-renewal and tumor targeting. Therefore, these cells may be valuable tools for clinical anticancer therapies as well. In a previous study, hAFSCs were used as cellular vehicles to deliver two suicide genes, CD and HSV-TK, and could possibly represent a novel targeted chemotherapy technique for treating breast cancer (56). The surface marker profile of hAFSCs and expression of the transcription factor Oct4 suggest that these cells exist in an intermediate stage between pluripotent human ES cells and lineage-restricted adult stem cells (57). Unlike ES cells, the process used to recover hAFSCs is not controversial. In addition, hAFSCs are associated with a low risk of tumorigenicity in vivo, implying that these cells may have more advantages that make them suitable for therapeutic applications against diverse human malignancies (57-61). In another study, the changes in proliferation and chemoresistance in engineered MSCs expressing transgene with enzymatic function were demonstrated, suggesting the possibilities for further augmentation of targeted MSC-mediated antitumor therapy (62).

In a previous investigation, treatment with engineered hAFSCs (AF2.CD-TK) and 5-FC/ganciclovir (GCV) had strong anticancer effects while original histological features of the breast tissue (e.g., the epidermis, dermis and reticular layers) were maintained (56). On the other hand, the structure of breast tissue treated with 5-FU was almost destroyed due to the potent cytotoxicity of the drug. Transgene therapies involving therapeutic or suicide genes are limited because most studies have used viral expression vectors such as adenoviral, retroviral or lentiviral vectors to deliver the suicide genes (e.g., ones encoding CD or TK). Although efficient, these viral delivery systems have unique limitations such as serum complement inactivation and detrimental mutations caused by random integration of the viral genome into the host genome $(63,64)$. Therefore, the need to design more accurate and safe delivery vectors is urgent. In addition, the anticancer effect of AF2.CD-TK cells on other types of cancers should be fully evaluated to broaden the therapeutic applications of these cells. Taken together, data from the literature have demonstrated that hAFSCs cells can be engineered to express the therapeutic CD and HSV-TK genes simultaneously, and administration of these GESTECs (AF2.CD-TK) significantly suppressed breast tumor growth after administration of the prodrugs 5-FC and GCV in both cellular and xenograft mouse models (56). Considering these promising results, AF2.CD-TK cells may be expected to have a therapeutic potential for selectively treating aggressive breast cancer by serving as cellular vehicles in a cell-based gene-directed enzyme prodrug system in breast cancer patients during the terminal stages.

\section{Other origins of stem cells}

Engineered MSCs obtained from bone marrow or the umbilical cord have been recently included in therapeutic tumor-targeting studies (65). These cells are capable of self-renewal and tissue reconstruction (66) and were genetically engineered to express either CD or IFN- $\beta$ as a delivery vehicle (67). The cells were found to possess tumor-tropic abilities that are attributed to the expression of growth factors, growth factor receptors, and chemokines $(52,67)$. The proliferation of several cancer cell lines including those derived from breast, lung and brain was 


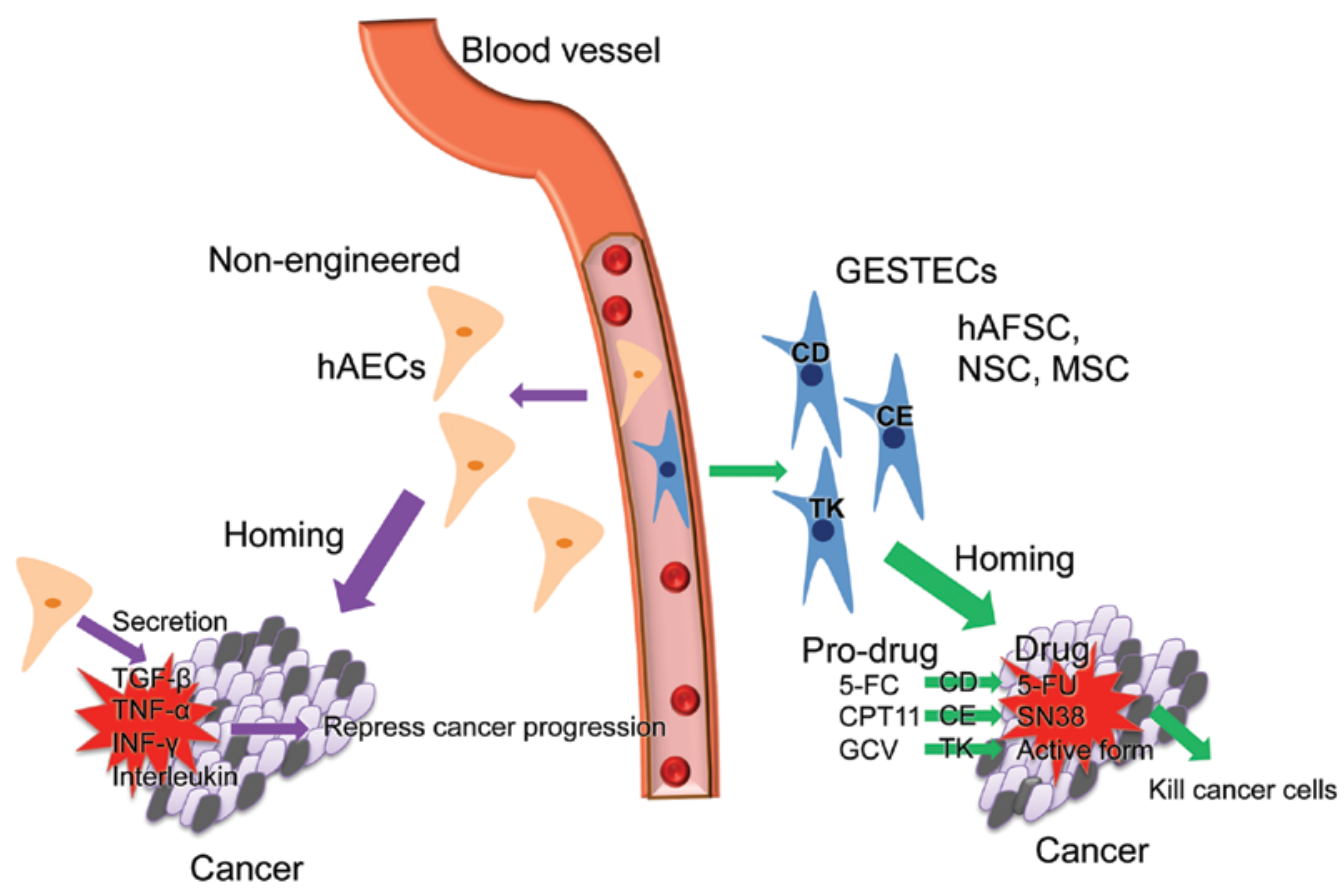

Figure 1. Strategies using GESTECs and non-GESTECs for selectively treating cancers. Stem cells have migration ability into cancer cells, repress the progression of cancer cells and induce apoptosis. Non-GESTECs, i.e., human amniotic membrane-derived epithelial stem cells (hAECs) produce TGF- $\beta$, TNF- $\alpha$, INF- $\gamma$ and various interleukins. These cytokines can repress cancer cell growth and induce apoptosis. In addition, GESTECs, such as AF2.CD-TK, HB1.F3.CE and HB1.F3 CD can migrate into cancer cells in the presence of ligand and receptor interactions for instance, various growth factors, chemokines and their receptors such as VEGF/VEGFR. These GESTECs have the CD, CE or TK gene which can convert prodrugs, i.e., 5-FC, CTP-11 and GCV, into active anticancer therapeutics, i.e., 5-FU, SN-38 and GCV active form, respectively. Consequently, GESTECs migrate into cancer cells and express enzymes containing $\mathrm{CD}, \mathrm{CE}$ and $\mathrm{TK}$ which produce cytotoxic drugs to directly kill cancer cells. These toxic drugs may selectively target cancer cells without harming neighboring normal cells. GESTECs, engineered stem cells; TGF- $\beta$, transforming growth factor $\beta$; TNF- $\alpha$, tumor necrosis factor- $\alpha$; CE, carboxyl esterase; TK, thymidine kinase; 5-FC, 5-fluorocytosine; GCV, ganciclovir.

inhibited in the presence of $\mathrm{CD}$ and 5-FC $(53,68)$. In particular, the therapeutic efficacy of GESTECs expressing IFN- $\beta$ was increased when the cells were administered 5-FU (53). Taken together, these data indicate that a specific and selective mediator or delivery system is critical for enhancing the targeted activity of prodrugs against de novo tumors (41).

Two types of NSCs, HB1.F3.CD and HB1.F3.CD.IFN- $\beta$ cells, may represent a novel approach for treating invasive tumors due to their inherent migratory and tumor-tropic properties as well as transgene expression (69-71). Since no effective treatments are available for most metastatic tumors, stem/progenitor cells expressing a suicide gene (CD) and cytokine (IFN- $\beta$ ) have the potential to improve the prognosis of patients with metastatic cancer (70).

\section{Conclusion}

Non-GESTECs without any introduction with therapeutic genes may have unique benefits for stem cell-based therapies because these cells are non-tumorigenic, are associated with low immunogenicity and have anti-inflammatory properties. Anticancer activities of NSCs as well as hAFSCs suggest that these cells are a novel and potential alternative tool for stem cell-based therapy. Human stem cell therapy using NSCs, hAESCs and hAFSCs include both a direct transplantation of non-GESTECs and a more complex application of genetically GESTECs designed for GEPT treatment or therapeutic gene delivery. For these strategies, stem cells from neural, amniotic membrane and amniotic fluid sources effectively target the primary tumors and suppress aggressive tumor growth by expressing various cytotoxic cytokines, such as TGF- $\beta$, TNF- $\alpha$, INF- $\gamma$ and interleukins (Fig. 1). In addition, these cells can also serve as novel delivery vehicles for the selective expression of therapeutic or suicide genes including IFN- $\beta, C D, C E$ and TK at primary and metastatic tumor sites for GEPT as shown in Fig. 1.

The mechanisms operating in various GEPT are different and therefore the biological properties of given cell types are important to be evaluated. Most GEPT employs viral vector mediated gene transfer protocols, which are usually limited by the restricted ability of the virus to track cancer cells infiltrating into the surrounding tissue and its low migratory capacity towards the tumor, implying that combination of cellular therapy and gene delivery is an attractive option (72). For GESTECs expressing prodrug-converting genes, the response of tumor cells associated with gap-junctional intercellular communication (GJIC) and expression of enzymes involved in drug metabolism and $\mathrm{ABC}$ transporters should be taken into consideration for the selection of the most efficient treatment strategy (73). Taken together, findings from the literature indicate that GESTECs including NSCs and ones from human amniotic membranes/fluid may exert potent antitumor effects via their tumor-tropic and tumoricidal actions. Therefore, these cells may be used as part of a novel strategy for selectively treating cancer patients with aggressive primary and metastatic malignancies. 


\section{Acknowledgements}

This study was supported by a National Research Foundation of Korea (NRF) grant (2013R1A1A2059092) funded by the Ministry of Education, Science and Technology (MEST) of the Republic of Korea. In addition, this study was also supported by a grant (no. PJ009599) from the Next-Generation BioGreen 21 Program, Rural Development Administration, Republic of Korea.

\section{References}

1. Saukkonen K and Hemminki A: Tissue-specific promoters for cancer gene therapy. Expert Opin Biol Ther 4: 683-696, 2004.

2. Evoy D, Hirschowitz EA, Naama HA, Li XK, Crystal RG Daly JM and Lieberman MD: In vivo adenoviral-mediated gene transfer in the treatment of pancreatic cancer. J Surg Res 69 226-231, 1997.

3. Kanai F, Lan KH, Shiratori Y, Tanaka T, Ohashi M, Okudaira T, Yoshida Y, Wakimoto H, Hamada $\mathrm{H}$, Nakabayashi $\mathrm{H}$, et al In vivo gene therapy for alpha-fetoprotein-producing hepatocellular carcinoma by adenovirus-mediated transfer of cytosine deaminase gene. Cancer Res 57: 461-465, 1997.

4. Li Z, Shanmugam N, Katayose D, Huber B, Srivastava S, Cowan K and Seth P: Enzyme/prodrug gene therapy approach for breast cancer using a recombinant adenovirus expressing Escherichia coli cytosine deaminase. Cancer Gene Ther 4: 113-117, 1997.

5. Etienne MC, Chéradame S, Fischel JL, Formento $P$, Dassonville O, Renée N, Schneider M, Thyss A, Demard F and Milano G: Response to fluorouracil therapy in cancer patients: The role of tumoral dihydropyrimidine dehydrogenase activity. J Clin Oncol 13: 1663-1670, 1995.

6. Castillo-Rodríguez RA, Arango-Rodríguez ML, Escobedo L, Hernandez-Baltazar D, Gompel A, Forgez P and MartínezFong D: Suicide HSVtk gene delivery by neurotensin-polyplex nanoparticles via the bloodstream and GCV treatment specifically inhibit the growth of human MDA-MB-231 triple negative breast cancer tumors xenografted in athymic mice. PLoS One 9: e97151, 2014

7. Freytag SO, Khil M, Stricker H, Peabody J, Menon M, DePeralta-Venturina M, Nafziger D, Pegg J, Paielli D, Brown S, et al: Phase I study of replication-competent adenovirus-mediated double suicide gene therapy for the treatment of locally recurrent prostate cancer. Cancer Res 62: 4968-4976, 2002.

8. Chung-Faye GA, Chen MJ, Green NK, Burton A, Anderson D, Mautner V, Searle PF and Kerr DJ: In vivo gene therapy for colon cancer using adenovirus-mediated, transfer of the fusion gene cytosine deaminase and uracil phosphoribosyltransferase. Gene Ther 8: 1547-1554, 2001

9. Fuchs C, Mitchell EP and Hoff PM: Irinotecan in the treatment of colorectal cancer. Cancer Treat Rev 32: 491-503, 2006.

10. Jaenisch R and Young R: Stem cells, the molecular circuitry of pluripotency and nuclear reprogramming. Cell 132: 567-582, 2008.

11. Thomson JA, Itskovitz-Eldor J, Shapiro SS, et al: Embryonic stem cell lines derived from human blastocysts. Science 282 1145-1147, 1998.

12. Gavrilov S, Papaioannou VE and Landry DW: Alternative strategies for the derivation of human embryonic stem cell lines and the role of dead embryos. Curr Stem Cell Res Ther 4: 81-86, 2009.

13. Khakoo AY, Pati S, Anderson SA, Reid W, Elshal MF, Rovira II, Nguyen AT, Malide D, Combs CA, Hall G, et al: Human mesenchymal stem cells exert potent antitumorigenic effects in a model of Kaposi's sarcoma. J Exp Med 203: 1235-1247, 2006.

14. Qiao L, Xu Z, Zhao T, Zhao Z, Shi M, Zhao RC, Ye L and Zhang X: Suppression of tumorigenesis by human mesenchymal stem cells in a hepatoma model. Cell Res 18: 500-507, 2008.

15. Brignier AC and Gewirtz AM: Embryonic and adult stem cell therapy. J Allergy Clin Immunol 125 (Suppl 2): S336-S344, 2010.

16. Aboody KS, Najbauer J and Danks MK: Stem and progenitor cell-mediated tumor selective gene therapy. Gene Ther 15: 739-752, 2008
17. Kim SK, Kim SU, Park IH, Bang JH, Aboody KS, Wang KC Cho BK, Kim M, Menon LG, Black PM, et al: Human neural stem cells target experimental intracranial medulloblastoma and deliver a therapeutic gene leading to tumor regression. Clin Cancer Res 12: 5550-5556, 2006.

18. Aboody KS, Bush RA, Garcia E, Metz MZ, Najbauer J, Justus KA, Phelps DA, Remack JS, Yoon KJ, Gillespie S, et al: Development of a tumor-selective approach to treat metastatic cancer. PLoS One 1: e23, 2006.

19. Fodde R: Stem cells and metastatic cancer: Fatal attraction? PLoS Med 3: e482, 2006.

20. Muller FJ, Snyder EY and Loring JF: Gene therapy: can neural stem cells deliver? Nat Rev Neurosci 7: 75-84, 2006.

21. Brown AB, Yang W, Schmidt NO, Carroll R, Leishear KK, Rainov NG, Black PM, Breakefield XO and Aboody KS: Intravascular delivery of neural stem cell lines to target intracranial and extracranial tumors of neural and non-neural origin. Hum Gene Ther 14: 1777-1785, 2003.

22. Lee DH, Ahn Y, Kim SU, Wang KC, Cho BK, Phi JH, Park IH, Black PM, Carroll RS, Lee J, et al: Targeting rat brainstem glioma using human neural stem cells and human mesenchymal stem cells. Clin Cancer Res 15: 4925-4934, 2009.

23. Zhao D, Najbauer J, Garcia E, Metz MZ, Gutova M, Glackin CA, Kim SU and Aboody KS: Neural stem cell tropism to glioma: Critical role of tumor hypoxia. Mol Cancer Res 6: 1819-1829, 2008.

24. Yi BR, Hwang KA, Aboody KS, Jeung EB, Kim SU and Choi KC Selective antitumor effect of neural stem cells expressing cytosine deaminase and interferon-beta against ductal breast cancer cells in cellular and xenograft models. Stem Cell Res 12: 36-48, 2014

25. Kim SU: Neural stem cell-based gene therapy for brain tumors. Stem Cell Rev 7: 130-140, 2011.

26. Dietrich J, Imitola J and Kesari S: Mechanisms of disease: The role of stem cells in the biology and treatment of gliomas. Nat Clin Pract Oncol 5: 393-404, 2008.

27. Auersperg N: Ovarian surface epithelium as a source of ovarian cancers: Unwarranted speculation or evidence-based hypothesis? Gynecol Oncol 130: 246-251, 2013.

28. Egami T, Ohuchida K, Miyoshi K, Mizumoto K, Onimaru M, Toma H, Sato N, Matsumoto K and Tanaka M: Chemotherapeutic agents potentiate adenoviral gene therapy for pancreatic cancer. Cancer Sci 100: 722-729, 2009.

29. Fu W, Lan H, Liang S, Gao T and Ren D: Suicide gene/prodrug therapy using salmonella-mediated delivery of Escherichia coli purine nucleoside phosphorylase gene and 6-methoxypurine 2'-deoxyriboside in murine mammary carcinoma 4T1 model. Cancer Sci 99: 1172-1179, 2008.

30. Kim KY, Kim SU, Leung PC, Jeung EB and Choi KC: Influence of the prodrugs 5-fluorocytosine and CPT-11 on ovarian cancer cells using genetically engineered stem cells: Tumor-tropic potential and inhibition of ovarian cancer cell growth. Cancer Sci 101: 955-962, 2010.

31. Consalvo M, Mullen CA, Modesti A, Musiani P, Allione A Cavallo F, Giovarelli $\mathrm{M}$ and Forni G: 5-Fluorocytosine-induced eradication of murine adenocarcinomas engineered to express the cytosine deaminase suicide gene requires host immune competence and leaves an efficient memory. J Immunol 154: 5302-5312, 1995

32. Freeman SM, Abboud CN, Whartenby KA, Packman $\mathrm{CH}$, Koeplin DS, Moolten FL and Abraham GN: The 'bystander effect': Tumor regression when a fraction of the tumor mass is genetically modified. Cancer Res 53: 5274-5283, 1993.

33. Jiang J, Wei D, Sun L, Wang Y, Wu X, Li Y, Fang Z, Shang H and Wei Z: A preliminary study on the construction of double suicide gene delivery vectors by mesenchymal stem cells and the in vitro inhibitory effects on SKOV3 cells. Oncol Rep 31: 781-787, 2014.

34. Dembinski JL, Wilson SM, Spaeth EL, Studeny M, Zompetta C, Samudio I, Roby K, Andreeff M and Marini FC: Tumor stroma engraftment of gene-modified mesenchymal stem cells as antitumor therapy against ovarian cancer. Cytotherapy 15: 20-32, 2013.

35. Engel JB, Keller G, Schally AV, Nagy A, Chism DD and Halmos G: Effective treatment of experimental human endometrial cancers with targeted cytotoxic luteinizing hormone-releasing hormone analogues AN-152 and AN-207. Fertil Steril 83 (Suppl 1): S1125-S1133, 2005.

36. Secord AA, Havrilesky LJ, O'Malley DM, Bae-Jump V, Fleming ND, Broadwater G, Cohn DE and Gehrig PA: A multicenter evaluation of sequential multimodality therapy and clinical outcome for the treatment of advanced endometrial cancer. Gynecol Oncol 114: 442-447, 2009. 
37. Carey MS, Gawlik C, Fung-Kee-Fung M, Chambers A, Oliver T; Cancer Care Ontario Practice Guidelines Initiative Gynecology Cancer Disease Site Group: Systematic review of systemic therapy for advanced or recurrent endometrial cancer. Gynecol Oncol 101: 158-167, 2006.

38. Fowler JM, Brady WE, Grigsby PW, Cohn DE, Mannel RS and Rader JS: Sequential chemotherapy and irradiation in advanced stage endometrial cancer: A Gynecologic Oncology Group phase I trial of doxorubicin-cisplatin followed by whole abdomen irradiation. Gynecol Oncol 112: 553-557, 2009.

39. Bruzzone M, Miglietta L, Franzone P, Gadducci A and Boccardo F: Combined treatment with chemotherapy and radiotherapy in high-risk FIGO stage III-IV endometrial cancer patients. Gynecol Oncol 93: 345-352, 2004

40. Kim SU, Nakagawa E, Hatori K, Nagai A, Lee MA and Bang JH: Production of immortalized human neural crest stem cells. Methods Mol Biol 198: 55-65, 2002.

41. Yi BR, Kang NH, Hwang KA, Kim SU, Jeung EB and Choi KC: Antitumor therapeutic effects of cytosine deaminase and interferon- $\beta$ against endometrial cancer cells using genetically engineered stem cells in vitro. Anticancer Res 31: 2853-2861, 2011.

42. Kim SU: Human neural stem cells genetically modified for brain repair in neurological disorders. Neuropathology 24: 159-171, 2004.

43. Jung S, Yi L, Kim J, Jeong D, Oh T, Kim CH, Kim CJ, Shin J, An S and Lee MS: The role of vimentin as a methylation biomarker for early diagnosis of cervical cancer. Mol Cells 31: 405-411, 2011

44. Arbyn M, Castellsagué X, de Sanjosé S, Bruni L, Saraiya M, Bray F and Ferlay J: Worldwide burden of cervical cancer in 2008. Ann Oncol 22: 2675-2686, 2011.

45. Francis SA and Katz ML: The HPV vaccine: A comparison of focus groups conducted in South Africa and Ohio Appalachia. Matern Child Health J 17: 1222-1229, 2013.

46. Kim HS, Yi BR, Hwang KA, Kim SU and Choi KC: Anticancer effects of the engineered stem cells transduced with therapeutic genes via a selective tumor tropism caused by vascular endothelial growth factor toward HeLa cervical cancer cells. Mol Cells 36: 347-354, 2013

47. Tammela T, Enholm B, Alitalo K and Paavonen K: The biology of vascular endothelial growth factors. Cardiovasc Res 65: 550-563 2005.

48. Ferrara N: Vascular endothelial growth factor: Basic science and clinical progress. Endocr Rev 25: 581-611, 2004.

49. Kang NH, Yi BR, Lim SY, Hwang KA, Baek YS, Kang KS and Choi KC: Human amniotic membrane-derived epithelial stem cells display anticancer activity in BALB/c female nude mice bearing disseminated breast cancer xenografts. Int J Oncol 40 : 2022-2028, 2012.

50. Coley HM: Mechanisms and strategies to overcome chemotherapy resistance in metastatic breast cancer. Cancer Treat Rev 34 378-390, 2008

51. Aboody KS, Najbauer J, Schmidt NO, Yang W, Wu JK, Zhuge Y, Przylecki W, Carroll R, Black PM and Perides G: Targeting of melanoma brain metastases using engineered neural stem/progenitor cells. Neuro Oncol 8: 119-126, 2006.

52. Rachakatla RS, Marini F, Weiss ML, Tamura M and Troyer D Development of human umbilical cord matrix stem cell-based gene therapy for experimental lung tumors. Cancer Gene Ther 14 828-835, 2007

53. Rachakatla RS, Pyle MM, Ayuzawa R, Edwards SM, Marini FC, Weiss ML, Tamura M and Troyer D: Combination treatment of human umbilical cord matrix stem cell-based interferon-beta gene therapy and 5-fluorouracil significantly reduces growth of metastatic human breast cancer in SCID mouse lungs. Cancer Invest 26: 662-670, 2008 .

54. Studeny M, Marini FC, Champlin RE, Zompetta C, Fidler IJ and Andreeff M: Bone marrow-derived mesenchymal stem cells as vehicles for interferon-beta delivery into tumors. Cancer Res 62 : 3603-3608, 2002.

55. Larmonier N, Ghiringhelli F, Larmonier CB, Moutet M, Fromentin A, Baulot E, Solary E, Bonnotte B and Martin F: Freshly isolated bone marrow cells induce death of various carcinoma cell lines. Int J Cancer 107: 747-756, 2003.
56. Kang NH, Hwang KA, Yi BR, Lee HJ, Jeung EB, Kim SU and Choi KC: Human amniotic fluid-derived stem cells expressing cytosine deaminase and thymidine kinase inhibits the growth of breast cancer cells in cellular and xenograft mouse models. Cancer Gene Ther 19: 412-419, 2012.

57. De Coppi P, Bartsch G Jr, Siddiqui MM, Xu T, Santos CC, Perin L, Mostoslavsky G, Serre AC, Snyder EY, Yoo JJ, et al: Isolation of amniotic stem cell lines with potential for therapy. Nat Biotechnol 25: 100-106, 2007.

58. Hajitou A, Trepel M, Lilley CE, Soghomonyan S, Alauddin MM, Marini FC III, Restel BH, Ozawa MG, Moya CA, Rangel R, et al: A hybrid vector for ligand-directed tumor targeting and molecular imaging. Cell 125: 385-398, 2006.

59. PhermthaiT, Odglun Y,Julavijitphong S, Titapant V, Chuenwattana $P$, Vantanasiri C and Pattanapanyasat K: A novel method to derive amniotic fluid stem cells for therapeutic purposes. BMC Cell Biol 11: 79, 2010.

60. Tamagawa T, Ishiwata I and Nakamura Y: Differentiation of human amniotic membrane cells into osteoblasts in vitro. Hum Cell 18: 191-195, 2005.

61. Zhang X, Chen X, Wang H and Liu S: Development of amniotic fluid-derived stem cell. Zhongguo Xiu Fu Chong Jian Wai Ke Za Zhi 22: 864-868, 2008 (In Chinese).

62. Kucerova L, Poturnajova M, Tyciakova S and Matuskova M: Increased proliferation and chemosensitivity of human mesenchymal stromal cells expressing fusion yeast cytosine deaminase. Stem Cell Res 8: 247-258, 2012.

63. Bi WL, Parysek LM, Warnick R and Stambrook PJ: In vitro evidence that metabolic cooperation is responsible for the bystander effect observed with HSV $t k$ retroviral gene therapy. Hum Gene Ther 4: 725-731, 1993.

64. Ishii-Morita H, Agbaria R, Mullen CA, Hirano H, Koeplin DA, Ram Z, Oldfield EH, Johns DG and Blaese RM: Mechanism of 'bystander effect' killing in the herpes simplex thymidine kinase gene therapy model of cancer treatment. Gene Ther 4: 244-251, 1997.

65. Zhao WH, Cheng JX, Shi PF and Huang JY: Human umbilical cord mesenchymal stem cells with adenovirus-mediated interleukin 12 gene transduction inhibits the growth of ovarian carcinoma cells both in vitro and in vivo. Nan Fang Yi Ke Da Xue Xue Bao 31: 903-907, 2011 (In Chinese).

66. Roufosse CA, Direkze NC, Otto WR and Wright NA: Circulating mesenchymal stem cells. Int J Biochem Cell Biol 36: 585-597, 2004.

67. Hu YL, Fu YH, Tabata Y and Gao JQ: Mesenchymal stem cells: A promising targeted-delivery vehicle in cancer gene therapy. J Control Release 147: 154-162, 2010.

68. Kim SU: Genetically engineered human neural stem cells for brain repair in neurological diseases. Brain Dev 29: 193-201, 2007.

69. Yi BR, Hwang KA, Kim YB, Kim SU and Choi KC: Effects of genetically engineered stem cells expressing cytosine deaminase and interferon-beta or carboxyl esterase on the growth of $\mathrm{LNCaP}$ prostate cancer cells. Int J Mol Sci 13: 12519-12532, 2012.

70. Yi BR, Kim SU, Kim YB, Lee HJ, Cho MH and Choi KC: Antitumor effects of genetically engineered stem cells expressing yeast cytosine deaminase in lung cancer brain metastases via their tumor-tropic properties. Oncol Rep 27: 1823-1828, 2012.

71. Yi BR, Park MA, Lee HR, Kang NH, Choi KJ, Kim SU and Choi KC: Suppression of the growth of human colorectal cancer cells by therapeutic stem cells expressing cytosine deaminase and interferon- $\beta$ via their tumor-tropic effect in cellular and xenograft mouse models. Mol Oncol 7: 543-554, 2013.

72. Duriniková E, Kučerová L and Matúšková M: Mesenchymal stromal cells retrovirally transduced with prodrug-converting genes are suitable vehicles for cancer gene therapy. Acta Virol 58: $1-13,2014$.

73. Matuskova M, Baranovicova L, Kozovska Z, Durinikova E, Pastorakova A, Hunakova L, Waczulikova I, Nencka R and Kucerova L: Intrinsic properties of tumour cells have a key impact on the bystander effect mediated by genetically engineered mesenchymal stromal cells. J Gene Med 14: 776-787, 2012. 